\title{
Reliability of Intraocular Pressure Measurement by Goldmann Applanation Tonometry After Refractive Surgery: A Review of Different Correction Formulas [Letter]
}

\author{
María Iglesias (iD) \\ Ricardo P Casaroli- \\ Marano (D) $^{2}$ \\ 'Ophthalmology Department, Hospital \\ Sant Rafael, Barcelona, 080 I2, Spain; \\ ${ }^{2}$ Department of Surgery, School of \\ Medicine and Hospital Clinic de \\ Barcelona, University of Barcelona (UB), \\ Barcelona, 08036, Spain
}

\section{Dear editor}

We have read with interest the article from de Bernardo et al titled Reliability of Intraocular Pressure Measurement by Goldmann Applanation Tonometry After Refractive Surgery: A Review of Different Correction Formulas. ${ }^{1}$

The authors provided a review of various correction formulas applied to Goldmann applanation tonometer (GAT) readings after the surgery, and other different methods to overcome underestimation of applanation tonometry after these procedures. In the discussion section of the paper, a description of several devices that attempted to find a reliable IOP post laser refractive surgery was described. They reference that there are four devices that have proven to be as reliable as GAT after surgery: dynamic contour tonometer (DCT), Corvis ST, Ocular Response Analyzer (ORA), and CATS.

Although the objective of the article was the described formulas, we would like to point out that a mention is missing among these tonometers. We have developed a new applanation tonometer that does not underestimate IOP after surgery: the Convex Tonometer (CT). ${ }^{2}$ We studied $n=102$ myopic laser refractive surgery patients (29 PRK, 73 LASIK) and CT had a strong correlation in the LASIK subgroup with GAT before surgery. Such outcome correlated as well with our finite element analysis, in which we found a lower resistance from the center of the cornea that encompassed a wider amount of contact between the operated cornea and GAT. However, if an external convex force with a determined radii was applied towards the operated cornea, a similar contact pressure profile could be registered.

We are ahead of new publications, and we acknowledge this tonometer is still not in the market, but since our article was published in April 2020 with such conclusions, we believe the authors could have at least referred our work in his paper.

In addition, there is another issue with the conclusions of this article: we disagree with the Bernardo et al that CATS prism has proven to be as reliable as GAT after laser procedures. In the article referred related to CATS tonometer, McCafferty et $\mathrm{al}^{3}$ measured with GAT and CATS $\mathrm{n}=243$ healthy eyes with a wide range of corneal pachymetry. They found a significant correlation between CCT and
Correspondence: María Iglesias Hospital Sant Rafael, Passeig de la Vall d'Hebron, 107, Barcelona, 08035, Spain Tel +34 628278996

Email mariaiglesiasalvarez@gmail.com 
$\mathrm{CH}$, improving IOP measurements related to corneal biomechanical changes due to $\mathrm{CCT}$ and $\mathrm{CH}$ variations. No post laser refractive surgery patients were included in this study. Indeed, McCafferty et al concluded that other studies will be carried out in laser refractive surgery patients and other subtype of patients. We coincide with the authors that this new tonometer has proven to be more reliable in standard corneas, but there are no publications about laser refractive surgery patients with the CATS device.

\section{Disclosure}

M. Iglesias, M.D, F.E.B.O, has exclusive personal rights to intellectual property of the convex tonometer secured by a European patent filed number 3520682 (awarded patent).
Ricardo P Casaroli-Marano M.D, Ph.D, declares no conflicts of interest in this communication.

\section{References}

1. De Bernardo M, Cembalo G, Rosa N. Reliability of intraocular pressure measurement by goldmann applanation tonometry after refractive surgery: a review of different correction formulas. Clin Ophthalmol. 2020;14:2783-2788. doi:10.2147/OPTH.S263856

2. Iglesias M, Yebra F, Kudsieh B, et al. New applanation tonometer for myopic patients after laser refractive surgery. Sci Rep. 2020;10:1-12. doi:10.1038/s41598-020-64013-4.

3. Mccafferty SJ, Tetrault K, McColgin A, et al. Modified Goldmann prism intraocular pressure measurement accuracy and correlation to corneal biomechanical metrics: multicentre randomised clinical trial. Br J Ophthalmol. 2019;103:1840-1844. doi:10.1136/bjophthalmol2018-313470

\footnotetext{
Dove Medical Press encourages responsible, free and frank academic debate. The content of the Clinical Ophthalmology 'letters to the editor' section does not necessarily represent the views of Dove Medical Press, its officers, agents, employees, related entities or the Clinical Ophthalmology editors. While all reasonable steps have been taken to confirm the content of each letter, Dove Medical Press accepts no liability in respect of the content of any letter, nor is it responsible for the content and accuracy of any letter to the editor.
}

\section{Publish your work in this journal}

Clinical Ophthalmology is an international, peer-reviewed journal covering all subspecialties within ophthalmology. Key topics include: Optometry; Visual science; Pharmacology and drug therapy in eye diseases; Basic Sciences; Primary and Secondary eye care; Patient Safety and Quality of Care Improvements. This journal is indexed on PubMed
Central and CAS, and is the official journal of The Society of Clinical Ophthalmology (SCO). The manuscript management system is completely online and includes a very quick and fair peer-review system, which is all easy to use. Visit http://www.dovepress.com/ testimonials.php to read real quotes from published authors. 